\title{
Lutein protects human retinal pigment epithelial cells from oxidative stress-induced cellular senescence
}

\author{
SEON YEONG CHAE ${ }^{1,2}$, SUN YOUNG PARK ${ }^{2}$ and GEUNTAE PARK ${ }^{1}$ \\ ${ }^{1}$ Department of Nanomaterials Engineering; ${ }^{2}$ Bio-IT Fusion Technology Research Institute, \\ Pusan National University, Busan 46241, Republic of Korea
}

Received June 25, 2018; Accepted September 24, 2018

DOI: $10.3892 / \mathrm{mmr} .2018 .9538$

\begin{abstract}
Oxidative stress-induced cellular senescence is an important contributor to the pathogenesis of age-related macular degeneration (AMD). Characteristics of premature cellular senescence include a loss of proliferation, change in cell shape, irreversible cell cycle arrest, and elevated senescence-associated $\beta$-galactosidase (SA- $\beta$-gal) activity. It was hypothesized that lutein may have anti-senescence potential and may be useful as a treatment for AMD. In the present study, premature cellular senescence was induced in ARPE-19 cells via treatment with $\mathrm{H}_{2} \mathrm{O}_{2}$ and the effects of lutein application were confirmed by observing cell morphology, lysosome contents, reactive oxygen species (ROS) generation and SA- $\beta$-gal activity, and cell cycle progression. The protein expression was also analyzed via western blotting in order to identify the affected signaling pathways. The results revealed that $\mathrm{H}_{2} \mathrm{O}_{2}$ treatment induced premature cellular senescence in ARPE-19 cells, as evidenced by an increased production of ROS and SA- $\beta$-gal, altered lysosome contents, changed cellular morphology and arrested cell cycle progression. However, when treated with lutein, ARPE-19 cells were effectively protected from these $\mathrm{H}_{2} \mathrm{O}_{2}$-induced effects. Western blot
\end{abstract}

Correspondence to: Professor Geuntae Park, Department of Nanomaterials Engineering, Pusan National University, 2 Busandaehak-ro 63 Beon-gil, South Gyeongsang, Busan 46241, Republic of Korea

E-mail: gtpark@pusan.ac.kr

Professor Sun Young Park, Bio-IT Fusion Technology Research Institute, Pusan National University, 2 Busandaehak-ro 63 Beon-gil, South Gyeongsang, Busan 46241, Republic of Korea

E-mail: sundeng99@pusan.ac.kr

Abbreviations: WST-1, water-soluble tetrazolium salt-1; CM- $\mathrm{H}_{2}$ DCFDA, chloromethyl derivative of 2',7'-dichlorodihydrofluorescein diacetate; ROS, reactive oxygen species; SA- $\beta$-gal, senescence-associated $\beta$-galatosidase; PI, Propidium iodide; HO- 1 , heme oxygenase-1; NQO1, NAD(P)H quinone dehydrogenase 1; Nrf2, nuclear factor erythroid 2-related factor 2; SIRT1, sirtuin-1; SIRT3, sirtuin-3

Key words: lutein, cellular senescence, $\mathrm{H}_{2} \mathrm{O}_{2}$, ARPE-19 cells, age-related macular degeneration analysis revealed that lutein induced the expression of heme oxygenase-1, NAD(P)H quinone dehydrogenase 1, sirtuin (SIRT)-1, and SIRT3. Together, the results indicated that lutein protects cells from cellular senescence induced by oxidative stress; therefore, it may be able to suppress the progression of AMD. In addition, our increased understanding of the pathways through which lutein acts is useful for the development of novel therapies for the treatment of oxidative stress-associated retinal disease.

\section{Introduction}

Age-related macular degeneration (AMD) is one of the most common causes of irreversible vision loss in the elderly population of developed countries (1,2). AMD is characterized by an accumulation of drusen in the macula, the thickening of Bruch's membrane, the denaturation of retinal pigment epithelial (RPE) cells, and abnormal angiogenesis, and is further complicated by choroidal neovascularization (CNV) (3). There are two types of AMD: wet AMD, which causes permanent vision damage despite therapeutic intervention, and dry AMD, which causes gradual blindness without specific treatment (4). In most cases, degeneration of the retinal pigment epithelium occurs, leading to death of the secondary photoreceptor and resulting in vision loss (5). Both genetic and environmental factors, such as persistent oxidative stress, smoking, excessive fat intake, and UV exposure, contribute to the development of AMD (6). In particular, oxidative stress and senescence are the leading causes of AMD. The retina experiences oxidative stress as a result of high oxygen tension, constant exposure to light, and a high proportion of unsaturated fatty acids contained within the photoreceptors (6). Although the main pathogenesis of AMD is unknown, oxidative stress has been reported as one of the leading causes and is also known to accelerate the process of aging, which again contributes to the development of AMD (2,3). In other words, aging and oxidative stress are anticipated to be critically involved in the pathogenesis of AMD.

Continuous oxidative stress could induce cellular senescence in RPE cells (6). It may also cause progressive cellular damage and inflammation, contributing to protein misfolding and functional anomalies in RPE cells during cellular senescence (1). Reactive oxygen species (ROS) are common free radicals that induce oxidative stress. Hypoxia, 
metabolic defects, oncogene activation, and ER stress are all factors that can contribute to the production of ROS. When ROS is produced in response to various endogenous or exogenous stressors, it contributes strongly to DNA damage, cell oxidation and apoptosis, cellular senescence, and eventually inflammation and tissue damage. The retina has a high metabolic activity and is composed of various lipid compounds and high oxygen concentrations. It is easy to generate ROS when exposed to persistent light and high oxygen. These ROS damage mitochondria and lipids, leading to modification of retinal functions (3).

Usually, cells will gradually lose the ability to divide as cellular proliferation declines, typically, fibroblasts divided up to 50 times. And cellular senescence is a process that limits this proliferation in normal cells (7), senescence only affects mitotic cells. Cellular senescence is characterized as an inability to proliferate despite the presence of sufficient nutrients but where cell viability and metabolic activity are still maintained (8). It is also a process through which cells undergo phenotypic changes, including chromatin alterations, tumor suppression, and interruption of cell division (9). Senescence is triggered by extreme cellular stress and may act as a protective mechanism against malignant cell degeneration. Common triggers for the onset of senescence are telomere shortening and dysfunction, DNA damage, oxidative stress, chromatin perturbations, oncogene activity, and strong mitogenic signals $(7,9)$. Thus, common traits of senescent cells are altered cell morphology, cell cycle arrest, DNA damage, tolerance to apoptosis, inflammatory protein secretion, activation of tumor-suppressing mechanisms, and changes in gene expression. Short-term cellular senescence is beneficial for tumor suppression, wound healing, and embryo development, but long-term cellular senescence promotes tumor formation and senescence-related diseases. Markers of cellular senescence include senescence-associated $\beta$-galactosidase (SA- $\beta$-gal), cell cycle arrest mechanisms, cell proliferation deficiency, DNA damage, DNA damage response activity, and various immune-related genes and cell regulatory factors. SA- $\beta$-gal is a representative senescence biomarker, as SA- $\beta$-gal activity is induced if cellular senescence occurs $(7,9)$.

Lutein is a kind of xanthophyll and one of the most prevalent carotenoids, which are a group of fat-soluble yellow pigments abundantly present in fruits and green vegetables (10). Lutein has protective effects against photo-oxidation and photo-destruction and is also known as a potent antioxidant. However, lutein cannot be synthesized human's body so must be ingested and absorbed. One unique characteristic of lutein is the fact that it exists in certain eye tissues. It is highly concentrated in the macula, a small part of the retina, and is the only carotenoid present in the tissue (11). Lutein is known as a powerful antioxidant that suppresses and scavenges ROS, acting as a filter for high energy blue light. By blocking harmful light, it prevents sun damage and promotes tumor cell death. Also, it has also been reported that ingestion of lutein is inversely related to the risk of developing eye diseases such as AMD and cataracts (11). In addition to eye health, recent studies have shown that lutein can help maintain heart health by reducing the risk of arteriosclerosis.

Given the existing known benefits of lutein, we sought to determine the anti-senescence efficacy of lutein treatment, and the mechanism by which such an effect might be mediated, using a premature cellular senescence model. In this study, we explored the effect of lutein on $\mathrm{H}_{2} \mathrm{O}_{2}$-induced premature senescence in RPE cells in order to determine whether it could counteract the induced oxidative stress and therefore provide a new therapeutic strategy for the treatment of AMD.

\section{Materials and methods}

Reagents. DMEM/F-12 medium (cat. no: LM002-04), was purchased from Welgene, Inc., (Daegu, Korea), FBS (fetal bovine serum, cat. no: 16000-044), penicillin-streptomycin (cat. no: 15140-122) and Trypsin-EDTA (cat. no: 15400-054) were purchased from Gibco; Thermo Fisher Scientific, Inc., (Waltham, MA, USA). Cell viability assay kit (D-Plus CCK; cat. no: CCK-1000) was purchased from Donginbio (Seoul, Korea). LysoTracker Green DND-26 (cat. no: 8783) was purchased from Cell Signaling Technology, Inc., (Danvers, MA, USA), and CM-H2DCFDA (chloromethyl derivative of 2',7'-dichlorodihydrofluorescein diacetate; cat. no: C6827) was purchased from Invitrogen; Thermo Fisher Scientific, Inc. Quantitative Cellular Senescence Assay kit (cat. no: CBA 232) was purchased from Cell Biolabs, Inc., (San Diego, CA), and senescence $\beta$-galactosidase staining kit (cat. no. 9860) was purchased from Cell Signaling Technology, Inc. PI (Propidium iodide solution; cat. no: p4864) was supplied from Sigma-Aldrich; Merck KGaA (Darmstadt, Germany). Bradford reagent (cat. no: 500-0006) was purchased from Bio-Rad Laboratories Inc., (Hercules, CA, USA), passive lysis buffer (cat. no: E194A) was acquired Promega Corporation (Madison, WI, USA). And primary antibodies; p-SIRT1 (cat. no: 2314), SIRT1 (cat. no: 9475), SIRT3 (cat. no: 5490), p-p53 (cat. no: 9286), p53 (cat. no: 2524), and p21 (cat. no: 2947) were obtained from Cell Signaling Technology, Inc. HO-1 (sc-10789), NQO1 (sc-16464), Nrf2 (sc-722), and $\alpha$-tubulin (sc-23948) were obtained from Santa Cruz Biotechnology, Inc., (Dallas, TX, USA). Secondary antibodies; anti-rabbit IgG, HRP-linked antibody (cat. no: 7074), anti-mouse IgG, HRP-linked antibody (cat. no: 7076) were obtained from Cell Signaling Technology, Inc.

Cell culture. The human RPE cell line ARPE-19 was incubated at $37^{\circ} \mathrm{C}$ with $5 \% \mathrm{CO}_{2}$ in DMEM/F-12 medium containing $10 \%$ heat-inactivated FBS and $1 \%$ antibiotics. Cells were passaged 2 to 3 times weekly, with experiments being performed on cells between passages 15 and 20 .

Cell viability assay. Cell viability was measured by WST-1 (water-soluble tetrazolium salt-1) assay. The WST-1 assay was performed the manufacturer's protocol. It is a colorimetric assay for the quantification of cell viability and proliferation, using the cleavage of the WST-1 by mitochondrial dehydrogenases. ARPE-19 cells were seeded in 24 well plates at a density of $4 \times 10^{4}$ cells/well. The cells were treated with $1,5,10$, and $20 \mu \mathrm{M}$ lutein and incubated at $37^{\circ} \mathrm{C}$ with $5 \% \mathrm{CO}_{2}$ for 24 , 48 , or $72 \mathrm{~h}$. After that $10 \mu \mathrm{l} \mathrm{CCK}-8$ solution was add to each well as and allow to react for $2 \mathrm{~h}$ at $37^{\circ} \mathrm{C}$ with $5 \% \mathrm{CO}_{2}$. The absorbance was measured at $450 \mathrm{~nm}$ using a microplate reader (Wallac 1420; PerkinElmer, Inc., Waltham, MA, USA). 
Treatment of cells with $\mathrm{H}_{2} \mathrm{O}_{2}$ and lutein. ARPE-19 cells were seeded in 6 well plates at a density of $1.5 \times 10^{5}$ cells/well, grown to $80 \%$ confluence, and treated with $100 \mu \mathrm{M} \mathrm{H}_{2} \mathrm{O}_{2}$ for $2 \mathrm{~h}$. They were then washed with PBS and incubated in normal growth medium for 3 days. Lutein treatment (indicated concentration) was applied $1 \mathrm{~h}$ prior to $\mathrm{H}_{2} \mathrm{O}_{2}$ treatment.

Lysosome contents and ROS generation. Cells that had been treated with both $\mathrm{H}_{2} \mathrm{O}_{2}(100 \mu \mathrm{M})$ and Lutein $(5,10$, and $20 \mu \mathrm{M})$ were washed with PBS and harvested using Trypsin-EDTA treatment. Lysosome contents were analyzed using $50 \mathrm{nM}$ LysoTracker Green DND-26 and ROS generation was analyzed using $2.5 \mu \mathrm{M}$ CM-H2DCFDA. CM-H2DCFDA was used to detect $\mathrm{H}_{2} \mathrm{O}_{2}$-induced ROS. Cells were treated with these dyes at room temperature in the dark for $30 \mathrm{~min}$. Fluorescence intensity was then measured by flow cytometry at an excitation wavelength of $488 \mathrm{~nm}$ and an emission wavelength of $525 \mathrm{~nm}$. Data analysis was performed using CXP software 2.0 (Beckman Coulter, Inc., Brea, CA, USA).

$S A-\beta$-gal activity and staining. Cells that had been treated with both $\mathrm{H}_{2} \mathrm{O}_{2}(100 \mu \mathrm{M}, 2 \mathrm{~h})$ and Lutein $(5,10$, and $20 \mu \mathrm{M})$ incubated for 3 days at $37^{\circ} \mathrm{C}$ with $5 \% \mathrm{CO}_{2}$. The SA- $\beta$-gal activity of $\mathrm{H}_{2} \mathrm{O}_{2}$ and lutein treated cells was evaluated using the Quantitative Cellular Senescence Assay Kit according to the manufacturer's protocol. Briefly, the cells were washed with PBS and harvested using Trypsin-EDTA before adding the pretreatment solution and incubating at $37^{\circ} \mathrm{C}$ with $5 \% \mathrm{CO}_{2}$ for $2 \mathrm{~h}$. They were then incubated with SA- $\beta$-gal substrate solution at $37^{\circ} \mathrm{C}$ with $5 \% \mathrm{CO}_{2}$ in the dark for $5 \mathrm{~h}$ before being analyzed using flow cytometry. Data analysis was performed using CXP software 2.0 (Beckman Coulter, Inc.).

The degree of SA- $\beta$-gal staining was observed using a senescence $\beta$-galactosidase staining kit. ARPE-19 cells were treated with lutein $(20 \mu \mathrm{M})$ for $1 \mathrm{~h}$, followed by $100 \mu \mathrm{M} \mathrm{H}_{2} \mathrm{O}_{2}$ treatment at $37^{\circ} \mathrm{C}$ with $5 \% \mathrm{CO}_{2}$ for $2 \mathrm{~h}$. The cells were washed with PBS, changed into normal growth medium, and then incubated with lutein at $37^{\circ} \mathrm{C}$ with $5 \% \mathrm{CO}_{2}$ for an additional 6 days. Finally, the treated cells were washed with PBS and fixed using fixative solution at room temperature for $20 \mathrm{~min}$. The cells were again washed with PBS and then incubated with $\beta$-galactosidase staining solution at $37^{\circ} \mathrm{C}$ overnight (no $\mathrm{CO}_{2}$ ). After incubation, the stained cells were observed under a microscope.

Cell cycle. ARPE-19 cells were seeded in $60 \mathrm{~mm}$ dishes at a density of $4 \times 10^{5}$ cells per dish. Cells were treated with lutein $(20 \mu \mathrm{M})$ for $1 \mathrm{~h}$, followed by $100 \mu \mathrm{M} \mathrm{H}_{2} \mathrm{O}_{2}$ treatment for $2 \mathrm{~h}$. After replacing to normal growth medium, the treated cells were again incubated with lutein at $37^{\circ} \mathrm{C}$ with $5 \% \mathrm{CO}_{2}$ for $48 \mathrm{~h}$, before being harvested using Trypsin-EDTA and fixed with $70 \%$ cold methanol at $4^{\circ} \mathrm{C}$ for $1 \mathrm{~h}$. They were then centrifuged $(2,000 \mathrm{rpm}$, $3 \mathrm{~min}$ ) and washed with PBS. Thereafter, $30 \mu \mathrm{g} / \mathrm{mL}$ RNase and PI were added to the cells and the cells were incubated at room temperature in the dark for $30 \mathrm{~min}$. Cell cycle analysis was performed using flow cytometry. Data analysis was performed using CXP software v2.0 (Beckman Coulter, Inc.).

Western blot analysis. ARPE-19 cells were seeded in $60 \mathrm{~mm}$ dishes at a density of $4 \times 10^{5}$ cells per dish. Cells were treated with lutein $(20 \mu \mathrm{M})$ for $1 \mathrm{~h}$, followed by $100 \mu \mathrm{M} \mathrm{H}_{2} \mathrm{O}_{2}$ treatment for $2 \mathrm{~h}$. After replacement with normal growth medium, the treated cells were incubated again with lutein at $37^{\circ} \mathrm{C}$ with $5 \% \mathrm{CO}_{2}$. Cells were collected using a scraper by adding RIPA buffer, and centrifuged (13,000 rpm, $10 \mathrm{~min})$ to lyse the cells, and obtained the protein. The protein content of cell lysates was determined using the Bradford reagent. Protein $(30 \mu \mathrm{g})$ from each sample was electrophoresed on 8.5 or $10 \%$ SDS-polyacrylamide gels, transferred to a PVDF (polyvinylidene difluoride) membrane. Membranes were incubated overnight at $4^{\circ} \mathrm{C}$ with the primary antibodies against p-SIRT1, SIRT1, SIRT3, p-p53, p53, and p21 (all 1:1,000). Also they were reacted for $4 \mathrm{~h}$ at room temperature with primary antibodies such as HO-1 (1:500), NQO1 (1:5,000), Nrf2 (1:1,000), and $\alpha$-tubulin $(1: 5,000)$. Secondary antibodies were used HRP-conjugated anti-rabbit, anti-mouse, or anti-goat antibodies (all 1:1,000) for $2 \mathrm{~h}$ at room temperature. Target bands were visualized using an enhanced chemiluminescence detection system (GE Healthcare, Chicago, IL, USA). Images were acquired using an ImageQuant 350 analyzer (GE Healthcare).

Statistical analysis. Statistical analyses were performed using SPSS (v23; IBM Corp., Armonk, NY, USA) to determine significant differences based on one-way analyses of variance (followed by Tukey's post-hoc test). $\mathrm{P}<0.05$ were considered to indicate a statistically significant difference.

\section{Results}

Cell viability. Cell viability of ARPE-19 cells treated with lutein at concentrations of 1 to $20 \mu \mathrm{M}$ for 24,48 , or $72 \mathrm{~h}$ were examined (Fig. 1). Cell viability was performed using the WST-1 assay. The WST results showed that lutein treatment at $20 \mu \mathrm{M}$ for $72 \mathrm{~h}$ resulted in no significant changes in viability when compared with the control.

Effects of lutein on lysosome contents and ROS generation in $\mathrm{H}_{2} \mathrm{O}_{2}$-treated ARPE-19 cells. The lysosome contents of ARPE-19 cells treated with $\mathrm{H}_{2} \mathrm{O}_{2}$ alone greatly increased (27.06\%) when compared with the control (10.44\%), whereas co-treatment with lutein resulted in a dose-dependent reduction $(22.34,17.08$, and $13.0 \%)$ when compared with the cells treated with $\mathrm{H}_{2} \mathrm{O}_{2}$ alone. Lutein treatment alone did not affect the lysosome contents of the cells (Fig. 2A). Lutein treatment alone did not affect ROS production (Fig. 2B). However, $\mathrm{H}_{2} \mathrm{O}_{2}$ treatment considerably increased ROS production (33.57\%) when compared to the normal control (10.42\%). Lutein treatment of $\mathrm{H}_{2} \mathrm{O}_{2}$ treated cells resulted in a marked decrease in expected ROS levels (26.03\%). These data suggest that oxidative stress is triggered in ARPE-19 cells by $\mathrm{H}_{2} \mathrm{O}_{2}$ and that this induction is inhibited by lutein. We have demonstrated that lutein suppresses $\mathrm{H}_{2} \mathrm{O}_{2}$-induced oxidative stress through anti-oxidative effects.

Inhibitory effects of lutein on SA- $\beta$-gal in $\mathrm{H}_{2} \mathrm{O}_{2}$-treated ARPE-19 cells. To evaluate the effects of lutein on $\mathrm{H}_{2} \mathrm{O}_{2}$-treated ARPE-19 cells, we employed SA- $\beta$-gal staining. The morphology and degree of staining were confirmed under a microscope. As indicated in Fig. 3A, normal cells did not show staining. However, after $\mathrm{H}_{2} \mathrm{O}_{2}$ treatment, changes in cell 


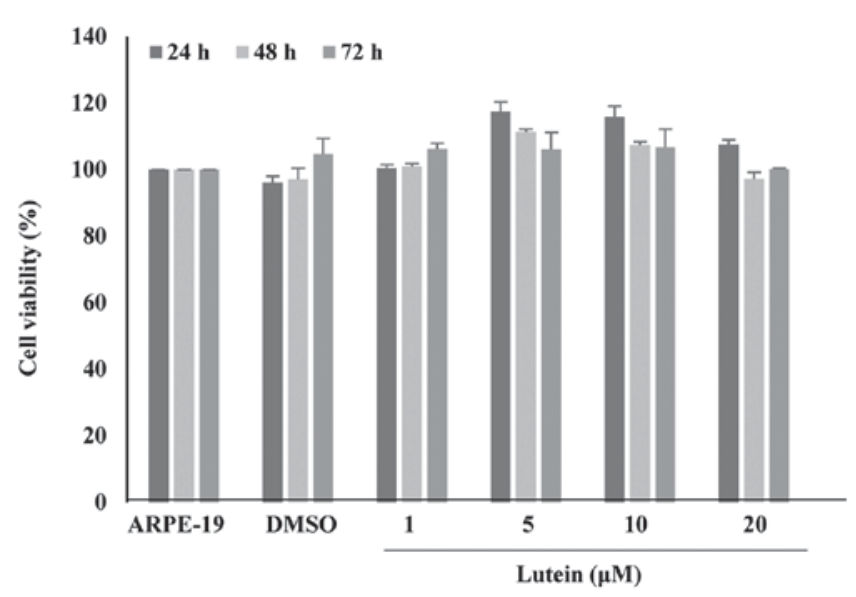

Figure 1. Cell viability. ARPE-19 cells were treated with the indicated concentrations of lutein for 24,48 or $72 \mathrm{~h}$ and cell viability was determined by water soluble tetrazolium salt 1 assay. Each bar represents the mean \pm standard error of three independent experiments per group. DMSO, dimethyl sulfoxide.

shape and an increase in SA- $\beta$-gal staining were observed. In cells treated with $\mathrm{H}_{2} \mathrm{O}_{2}$ and lutein, the SA- $\beta$-gal staining was considerably decreased, while lutein treatment alone did not produce $\mathrm{SA}-\beta$-gal staining. Thus, $\mathrm{H}_{2} \mathrm{O}_{2}$ induced senescence in ARPE-19 cells and lutein greatly inhibited the production of SA- $\beta$-gal in cells induced towards senescence by $\mathrm{H}_{2} \mathrm{O}_{2}$ treatment, indicating that lutein protected ARPE-19 cells from $\mathrm{H}_{2} \mathrm{O}_{2}$-induced senescence.

To evaluate the effects of lutein on $\mathrm{H}_{2} \mathrm{O}_{2}$-treated ARPE-19 cells, SA- $\beta$-gal activity was measured. As shown in Fig. 3B, the number of SA- $\beta$-gal positive cells increased in cells treated with $\mathrm{H}_{2} \mathrm{O}_{2}(41.08 \%)$ to a level roughly four-fold higher than is seen in normal control cells. In cells treated with both $\mathrm{H}_{2} \mathrm{O}_{2}$ and lutein, the number of SA- $\beta$-gal positive cells was effectively decreased, in a lutein-dose-dependent manner $(35.38,27.39$, and $20.41 \%)$. In cells treated with lutein alone, the number of SA- $\beta$-gal positive cells did not increase. These data show that SA- $\beta$-gal positive cells are increased in cells triggered for senescence by $\mathrm{H}_{2} \mathrm{O}_{2}$ and that this effect is markedly decreased by lutein treatment. Together, these data clearly indicate the inhibitory effects of lutein treatment on $\mathrm{H}_{2} \mathrm{O}_{2}$-induced senescence.

Cell cycle analysis of lutein and $\mathrm{H}_{2} \mathrm{O}_{2}$-treated ARPE-19 cells. Oxidative stress and the resulting DNA damage can contribute to cell cycle arrest in senescent cells. Therefore, we performed cell cycle analysis using PI staining to assess the effects of lutein on $\mathrm{H}_{2} \mathrm{O}_{2}$-treated ARPE-19 cells. We observed $\mathrm{G} 2$ arrest after $\mathrm{H}_{2} \mathrm{O}_{2}$ treatment. Lutein treatment significantly attenuated the percentage of $\mathrm{G} 2$ arrest observed in these $\mathrm{H}_{2} \mathrm{O}_{2}$-treated cells but did not affect the cell cycle distribution in control cells (Fig. 4). These data indicate that G2 arrest is increased in ARPE-19 cells by $\mathrm{H}_{2} \mathrm{O}_{2}$ treatment, however, this is reversed by lutein treatment. Thus, these results clearly support the hypothesis that lutein protects ARPE-19 cells from DNA damage caused by $\mathrm{H}_{2} \mathrm{O}_{2}$-induced oxidative stress.

Induction of HO-1, NQO1, and Nrf2 in ARPE-19 cells. When oxidative stress occurs, Nrf2 is activated, followed by the expression of antioxidant enzymes such as HO-1 and
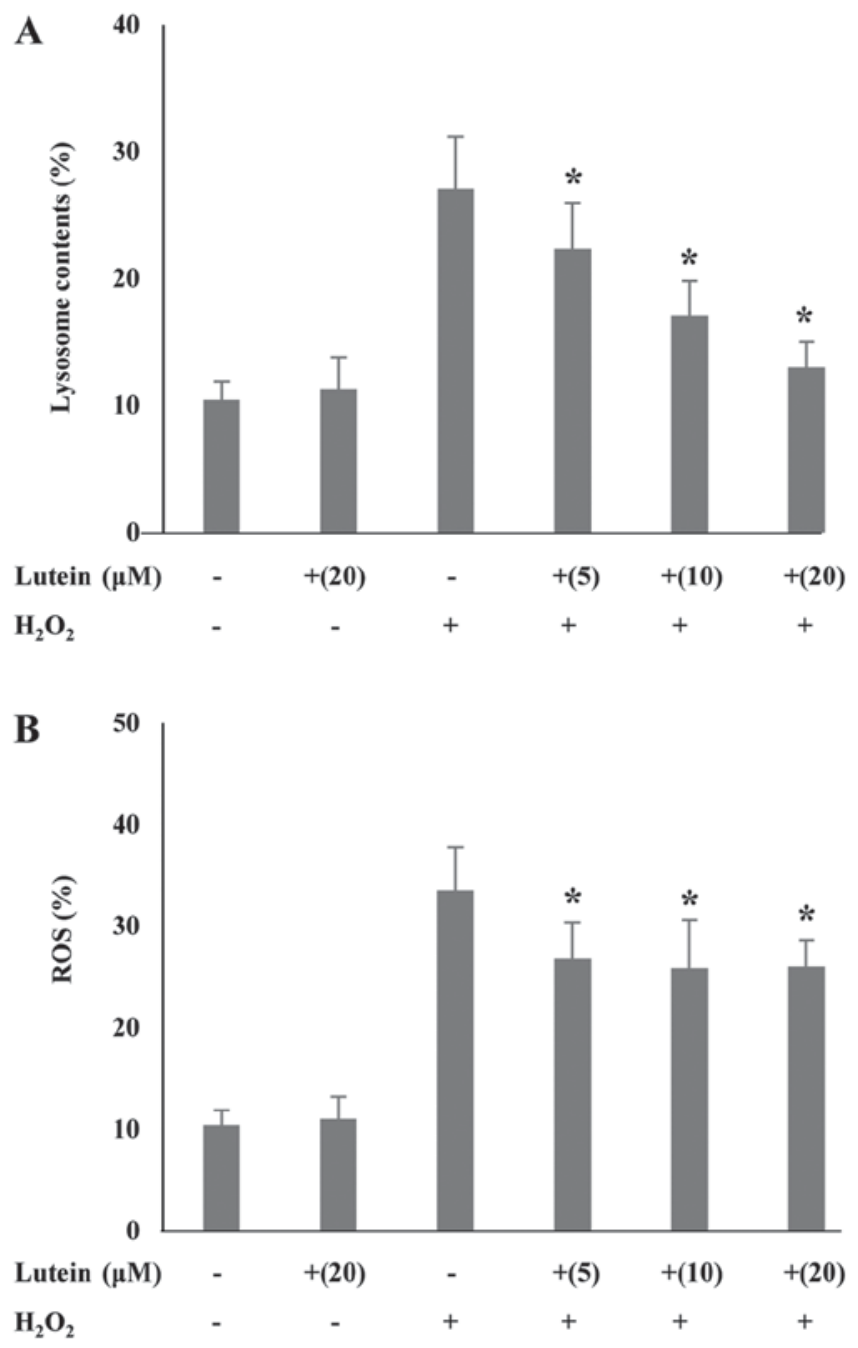

Figure 2. Effects of lutein on $\mathrm{H}_{2} \mathrm{O}_{2}$-induced ARPE-19 cells. ARPE-19 cells were pretreated with the indicated concentrations of lutein for $1 \mathrm{~h}$ and treated with $100 \mu \mathrm{M} \mathrm{H}_{2} \mathrm{O}_{2}$ for $2 \mathrm{~h}$, followed by a 3 day incubation. (A) Lysosome contents and (B) intracellular ROS levels were quantified via DND-26 and CM- $\mathrm{H}_{2}$ DCFDA. Lysosome contents and ROS generation were determined by flow cytometry. Each bar represents the mean \pm standard error of three independent experiments per group. ${ }^{*} \mathrm{P}<0.05$ vs. the $\mathrm{H}_{2} \mathrm{O}_{2}$-treated group. $\mathrm{H}_{2} \mathrm{O}_{2}$, hydrogen peroxide; ROS, reactive oxygen species.

NQO1. We observed the induction of HO-1 and NQO1, and the activation of Nrf2, upon lutein treatment. These effects are most strongly observed at 8,4 , and $1 \mathrm{~h}$ after lutein treatment, respectively (Fig. 5A and C). Furthermore, HO-1 and NQO1 were most strongly expressed at lutein treatment levels of 10 or $20 \mu \mathrm{M}$ (Fig. 5B). HO-1 and NQO1 are both known to be involved in protecting cells from various stresses. These results indicate that $\mathrm{HO}-1$ induction via lutein may activate cellular protective and/or anti-oxidative effects.

Expression of p53, p21 in $\mathrm{H}_{2} \mathrm{O}_{2}$-treated ARPE-19 cells. We observed changes in the protein expression of p53 and p21 following lutein treatment in $\mathrm{H}_{2} \mathrm{O}_{2}$-treated ARPE-19 cells. As shown in Fig. $6 \mathrm{~A}$ and $\mathrm{B}$, the phosphorylation of $\mathrm{p} 53$ protein was slightly elevated by $\mathrm{H}_{2} \mathrm{O}_{2}$ treatment, and this was reduced by $20 \mu \mathrm{M}$ lutein treatment, but this was not a statistically significant decrease. The expression of $\mathrm{p} 21$ protein was also increased after treatment with $\mathrm{H}_{2} \mathrm{O}_{2}$, but this change was markedly decreased 

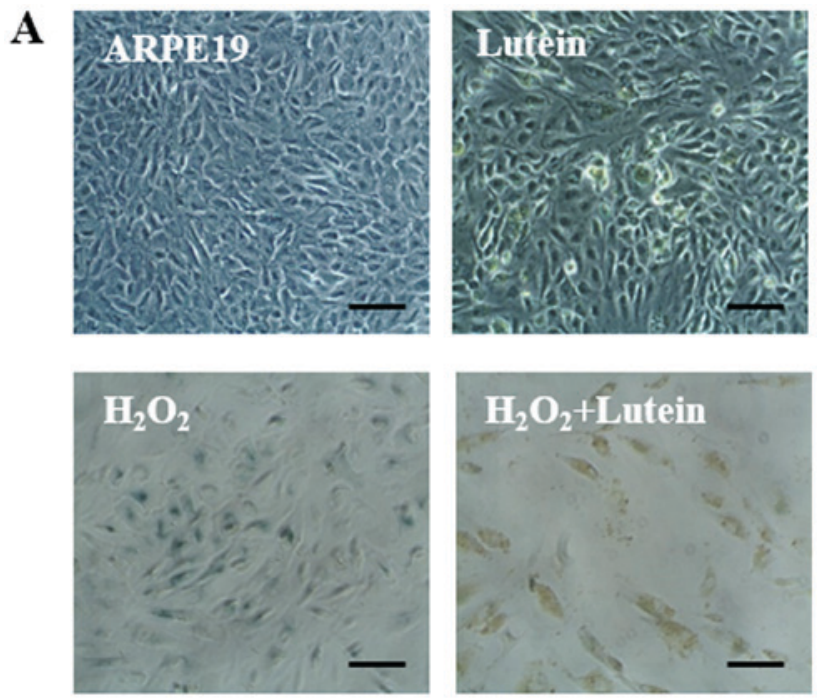

B

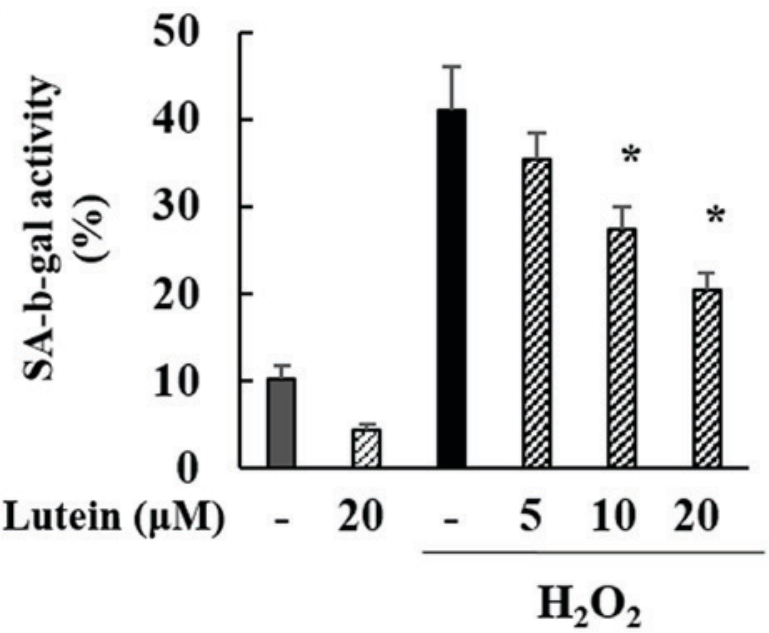

Figure 3. Effects of lutein on $\mathrm{H}_{2} \mathrm{O}_{2}$-induced ARPE-19 cells. (A) SA- $\beta$-gal staining. ARPE-19 cells were pretreated with $20 \mu \mathrm{M}$ lutein for $1 \mathrm{~h}$, followed by treatment with $100 \mu \mathrm{M} \mathrm{H}_{2} \mathrm{O}_{2}$ for $2 \mathrm{~h}$ and a 6 day incubation. SA- $\beta$-gal staining was performed using $\mathrm{x}$-gal and was observed under a microscope (scale bars, $100 \mu \mathrm{m}$ ). (B) SA- $\beta$-gal activity. ARPE-19 cells were pretreated with the indicated concentrations of lutein for $1 \mathrm{~h}$ prior to treatment with $100 \mu \mathrm{M} \mathrm{H}_{2} \mathrm{O}_{2}$ for $2 \mathrm{~h}$ followed by 3 days of incubation. SA- $\beta$-gal activity was determined by flow cytometry. Each bar represents the mean \pm standard error of three independent experiments per group. ${ }^{*} \mathrm{P}<0.05$ vs. the $\mathrm{H}_{2} \mathrm{O}_{2}$-treated group. $\mathrm{H}_{2} \mathrm{O}_{2}$, hydrogen peroxide; SA- $\beta$-gal, senescence-associated $\beta$-galactosidase.

by lutein treatment in a dose-dependent manner (Fig. 6B). Especially p21 showed a statistically significant decrease at high concentrations. These data suggest that the p53-p21 pathway is significantly activated by $\mathrm{H}_{2} \mathrm{O}_{2}$, meaning that cell cycle changes and cellular senescence may be induced via the $\mathrm{p} 53$-p21 pathway. Lutein appears effective in controlling the p53-p21 pathway in these $\mathrm{H}_{2} \mathrm{O}_{2}$-induced cells.

Expression of SIRT1 and SIRT3 in $\mathrm{H}_{2} \mathrm{O}_{2}$-treated ARPE-19 cells. Sirtuins are typical aging-related proteins that affect cellular processes. We confirmed that SIRT1 and SIRT3 expression is regulated by lutein exposure in $\mathrm{H}_{2} \mathrm{O}_{2}$-treated ARPE-19 cells. SIRT3 was increased by $\mathrm{H}_{2} \mathrm{O}_{2}$ and lutein treatment (Fig. B), suggesting that lutein is associated with the inhibition of senescence. Also, as shown in Fig. 6A, the phosphorylation of SIRT1 increased after treatment with $\mathrm{H}_{2} \mathrm{O}_{2}$ and lutein in a

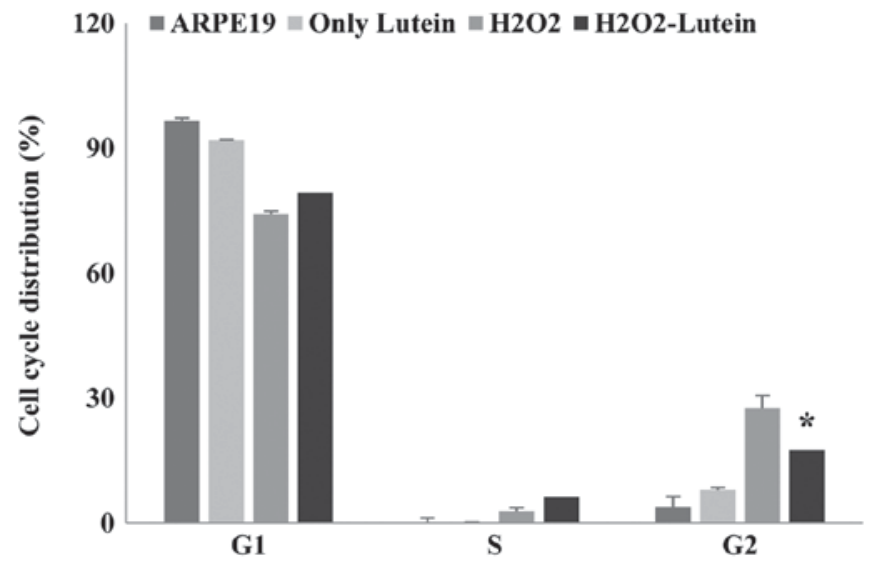

Figure 4. Cell cycle analysis. ARPE-19 cells were pretreated with $20 \mu \mathrm{M}$ lutein for $1 \mathrm{~h}$ prior to treatment with $100 \mu \mathrm{M} \mathrm{H}_{2} \mathrm{O}_{2}$ for $2 \mathrm{~h}$, followed by a $48 \mathrm{~h}$ incubation. Cells were fixed in $70 \%$ methanol and stained with propidium iodide prior to analysis by flow cytometry. Each bar represents the mean \pm standard error of three independent experiments per group. ${ }^{*} \mathrm{P}<0.05$ vs. the $\mathrm{H}_{2} \mathrm{O}_{2}$-treated group. $\mathrm{H}_{2} \mathrm{O}_{2}$, hydrogen peroxide.

dose-dependent manner. Therefore, our data indicate that the protective effects of lutein against $\mathrm{H}_{2} \mathrm{O}_{2}$-induced senescence are partially controlled through the up-regulation of SIRT1 and SIRT3.

\section{Discussion}

The purpose of this study was to investigate the effects of lutein on occurred cellular senescence and oxidative stress induced by $\mathrm{H}_{2} \mathrm{O}_{2}$ treatment as well as to determine which activation pathways lutein may act through. Oxidative stress occurs when there is an imbalance between antioxidants and free radicals, leading to an increase in free radicals. ROS, a group of prevalent free radicals, are induced by hypoxia, ER stress, metabolic defect, and oncogene activation. Scavenging factors include Nrf2, glutathione, NADPH, and tumor suppressor mechanisms. Excessive ROS lead to senescence processes by promoting DNA damage and cellular oxidation, while also contributing to the pathogenesis of various diseases. Oxidative stress is an active field of research due to its involvement in various diseases, including sepsis, mastitis, enteritis, pneumonia, and respiratory and joint diseases (12).

Senescence-associated beta-galactosidase (SA- $\beta$-gal) is a hydrolytic enzyme that catalyzes only in senescent cells. Specifically, SA- $\beta$-galactosidase is overexpressed and accumulated in senescent cells, therefore the most widely used biomarkers of senescence and was the first marker for the detection of senescence and senescent cells. Hydrogen peroxide $\left(\mathrm{H}_{2} \mathrm{O}_{2}\right)$ is a typical oxidizing agent and simplest peroxide, which causes ROS, which can cause disease. $\mathrm{H}_{2} \mathrm{O}_{2}$ induces oxidative stress by increasing lysosome contents and ROS generation. Premature cellular senescence is confirmed by the detection of increasing number of SA- $\beta$-gal positive cells. The present study demonstrated that $\mathrm{H}_{2} \mathrm{O}_{2}$ treatment induced oxidative stress in ARPE-19 cells, leading to cellular senescence. Lutein was applied at a various concentrations but had no effect on cell viability at any of the treatment concentrations or times. Lutein treatment markedly decreased lysosome contents and ROS generation in a dose-dependent manner 

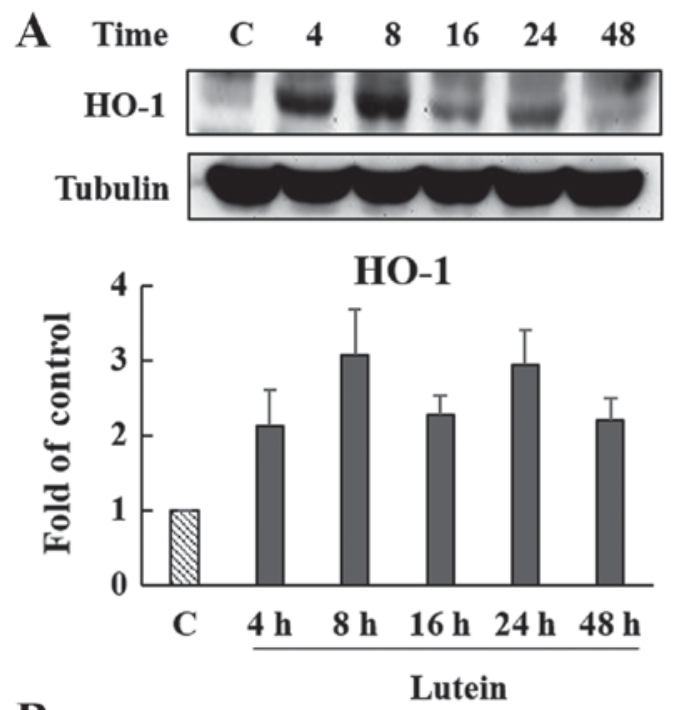

B
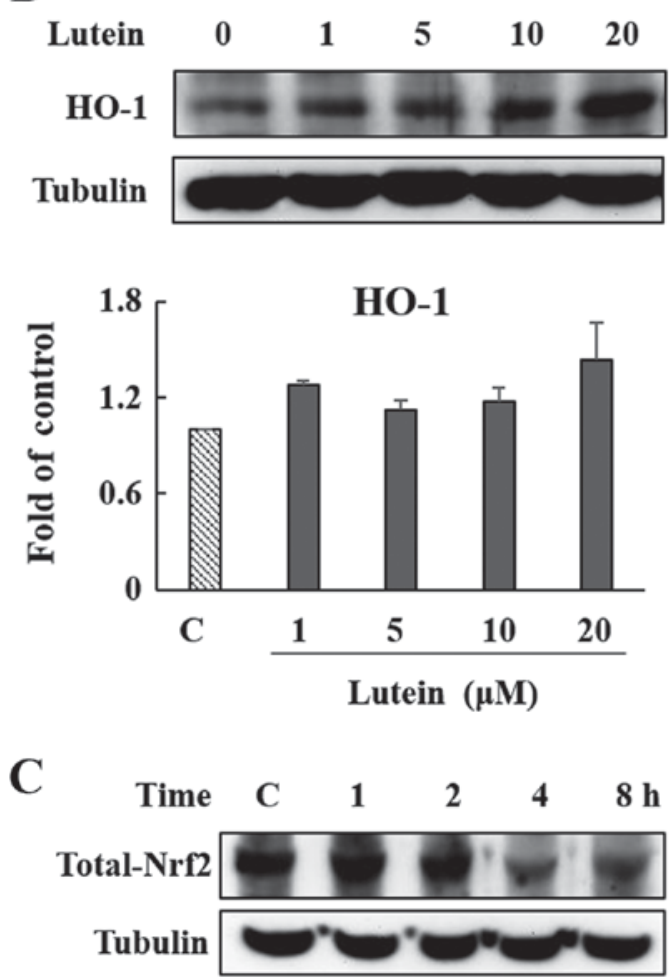
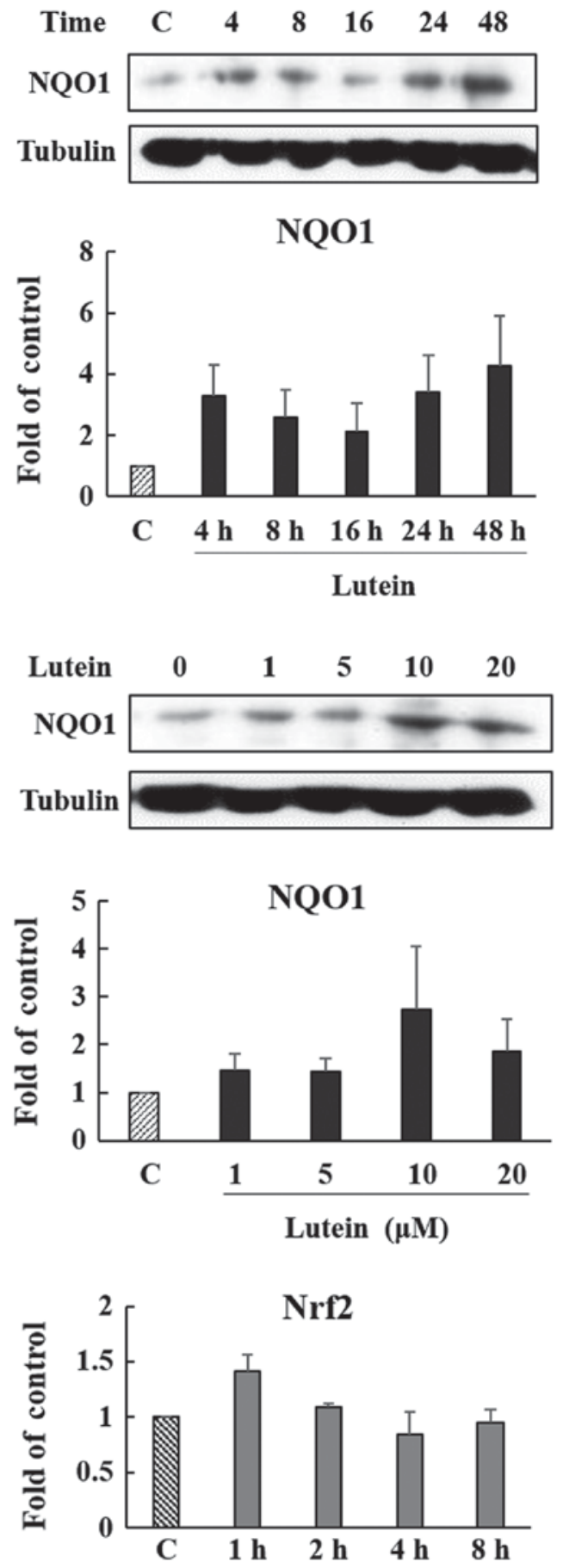

Figure 5. Effect of lutein on the expression of HO-1 and NQO1, and the activation of Nrf2. (A) ARPE-19 cells were treated with $20 \mu \mathrm{M}$ of lutein for the indicated times. Following incubation, cells were harvested and HO-1 and NQO1 were determined by western blotting. (B) ARPE-19 cells were treated with the indicated concentrations of lutein for $8 \mathrm{~h}$, then HO-1 and NQO1 levels were determined by western blotting. (C) ARPE-19 cells were treated with $20 \mu \mathrm{M}$ of lutein for the indicated times. Following incubation, cells were harvested and Nrf2 was determined by western blotting. The ratios of $\alpha$-tubulin to HO-1, NQO1 and Nrf2 were determined by densitometry. Each bar represents the mean \pm standard error of three independent experiments per group. HO-1, heme oxygenase-1; NQO1, NAD(P)H quinone dehydrogenase 1; Nrf2, nuclear factor erythroid 2-related factor 2; Ctrl, control.

and SA- $\beta$-gal positive cells were also considerably decreased. Our results demonstrate that lutein treatment suppresses ROS and decreases SA- $\beta$-gal positive cells. In other words, lutein protects ARPE-19 cells from senescence caused by $\mathrm{H}_{2} \mathrm{O}_{2}$-induced oxidative stress. In this $\mathrm{H}_{2} \mathrm{O}_{2}$-induced cellular senescence model, lutein suppressed the expected increase of cellular ROS, lysosome contents and SA- $\beta$-gal positive cells as part of its protective effects on ARPE-19 cells.
Nrf2 binds to keap1 and is inactivated, when oxidative stress such as ROS occurs, it is activated and dissociates and moves into the nucleus. And induces the expression of antioxidant enzymes such as HO-1, NQO1 and SOD. Heme oxygenase is an enzyme that catalyzes the degradation of heme and produces biliverdin, iron, and carbon monoxide (13). HO-1 (Heme oxygenase-1) and NQO1 (NAD(P)H dehydrogenase 1) are important antioxidant enzymes. HO-1 and its byproducts 
A
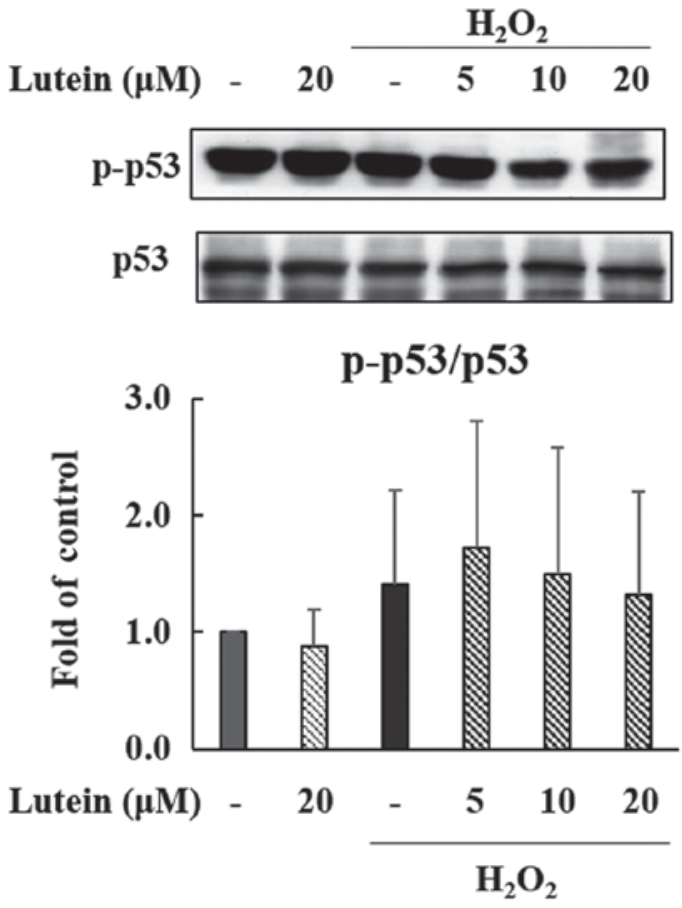
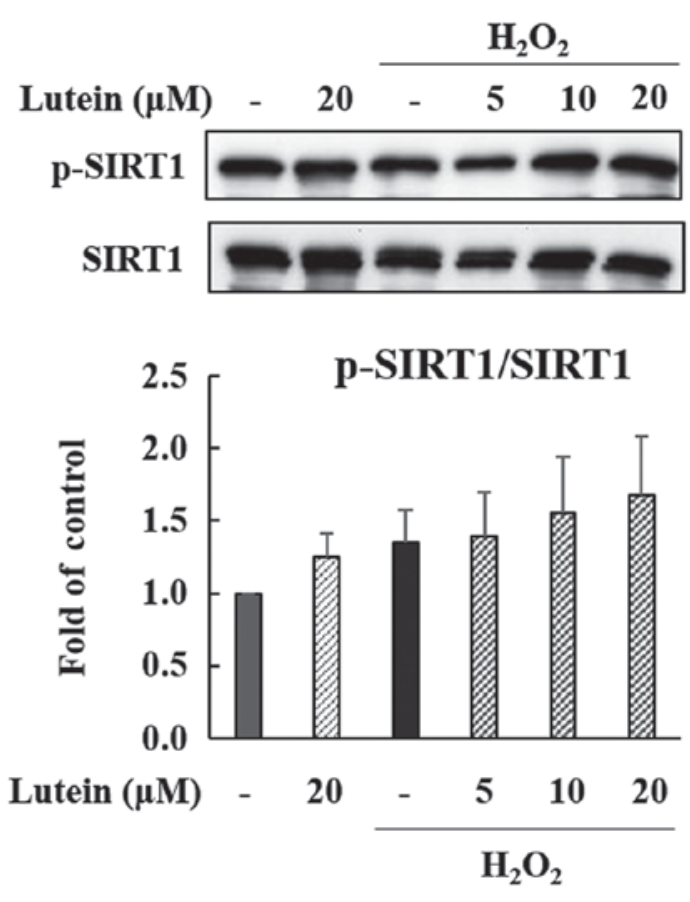

B
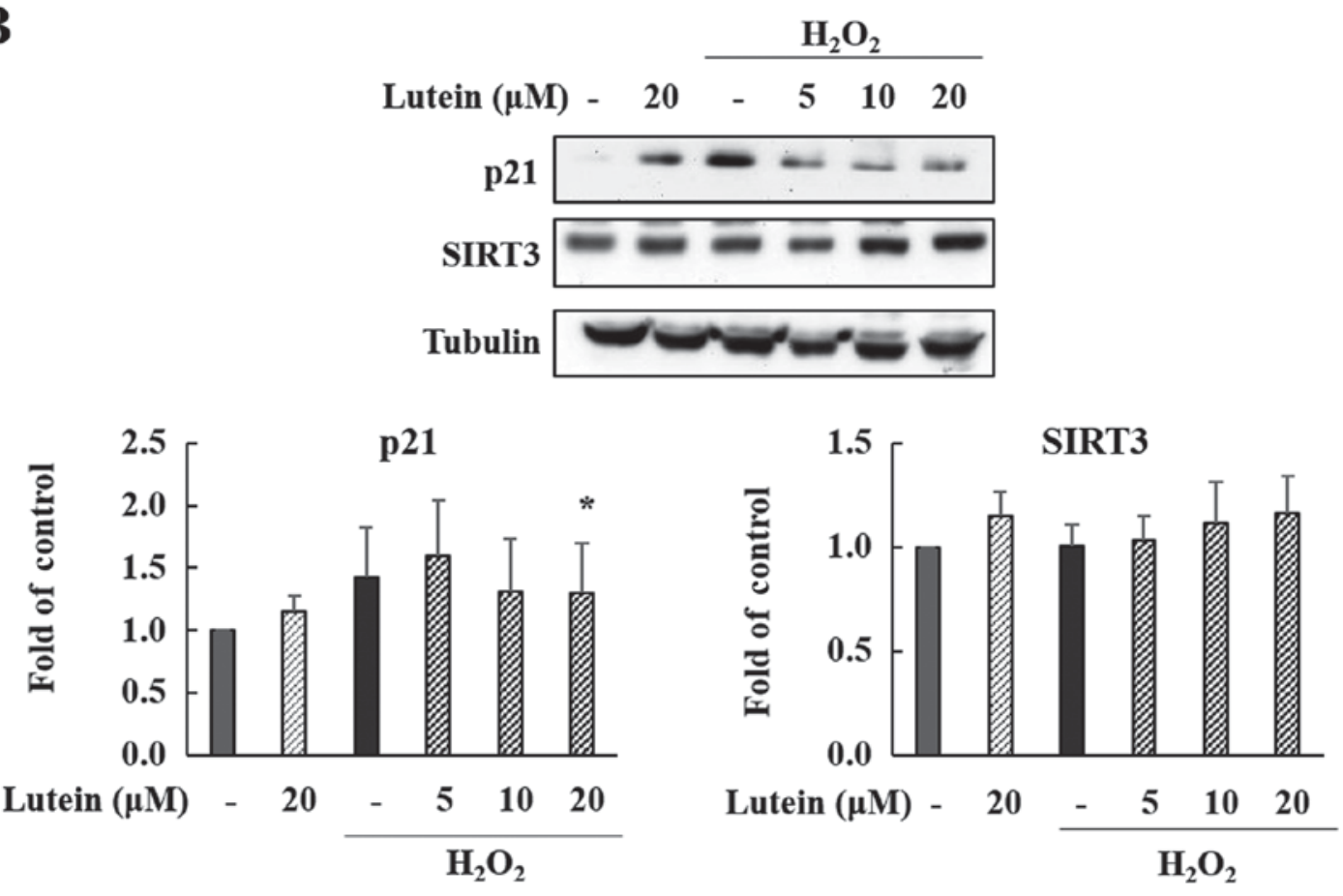

Figure 6. Effect of lutein on the $\mathrm{H}_{2} \mathrm{O}_{2}$-induced activation of p53, p21, SIRT1 and SIRT3. Lutein was pretreated at the indicated concentrations for $1 \mathrm{~h}$ prior to treatment with $100 \mu \mathrm{M} \mathrm{H}_{2} \mathrm{O}_{2}$ for $2 \mathrm{~h}$. Following incubation, cells were harvested, and (A) p-p53 and p-SIRT1 and (B) p21 and SIRT3 expressions were determined by western blotting. Each bar represents the mean \pm standard error of three independent experiments per group. * $\mathrm{P}<0.05$ vs. the $\mathrm{H}_{2} \mathrm{O}_{2}$-treated group. $\mathrm{H}_{2} \mathrm{O}_{2}$, hydrogen peroxide; p-, phosphorylated; SIRT, sirtuin.

play major roles in the regulation of oxidative stress and inflammation. In addition, it is known to mediate cellular defense mechanisms against diverse stresses $(14,15)$. NQO1 is part of the defense systems cells employ against oxidative stress. Therefore, HO-1 and NQO1 are major enzymes that play important roles in the intracellular, antioxidant defense systems of cells. The induction of HO-1 and NQO1 is considered to be cell-protective. Our study clearly indicates that lutein induces HO-1 and NQO1 activation in ARPE-19 cells.
The $\mathrm{p} 53$ and $\mathrm{p} 21$ proteins are important to signaling pathways in the DNA damage-related senescence response and are also known to regulate apoptosis, be involved in cell cycling, and are well known tumor suppressors (16). The p21 also known as cyclin-dependent kinase inhibitor 1 , it is a leading target of p53 activity, also is associated with linking DNA damage to cell cycle arrest. Upon DNA damage, the p53 protein is activated and in turn induces expression of p21. Activation of p21 can cause cell cycle arrest and block cell growth (17). 
Lutein restored cell cycling in cells induced towards cellular senescence via down-regulation of p53 and thus also p21. Cell cycle analysis also showed that $\mathrm{H}_{2} \mathrm{O}_{2}$ induced cell cycle arrest was restored by lutein treatment.

Sirtuins are known to affect cellular processes in response to cellular senescence, transcription, inflammation and apoptosis and various stresses (18). SIRT1 is a well-known senescence regulator that facilitates DNA damage repair in mouse and, in particular, is reported to play a critical role in senescence processes of the murine retina. In addition, SIRT1 activation decreases in the retina are followed by the accumulation of DNA damage (2). Our results suggest that lutein exerts effects on ARPE-19 cells though SIRT1 activation, protecting them from senescence by oxidative stress. The activation of SIRT1 also leads to reductions in the levels of p53 and p21. SIRT3 has been reported to support the maintenance of suitable mitochondrial function by limiting oxidative stress and by reducing ROS generation (19). Lutein treatment also increased the activity of SIRT3, again supporting the hypothesis that lutein protects ARPE-19 cells against $\mathrm{H}_{2} \mathrm{O}_{2}$-induced cellular senescence. Our results indicate that activation of SIRT1 and SIRT3 also contribute to the anti-senescence functions of lutein. And, in turn, lutein may promote the expression and activation of SIRT1 and SIRT3.

Summarize, we analyzed on the production of intracellular ROS in order to confirm the effect of lutein on the cellular redox status. As a result, ROS generation is increased by $\mathrm{H}_{2} \mathrm{O}_{2}$, and lutein was decreased in a dose-dependent manner. The antioxidative effect of lutein was confirmed through this results. Also, in our western results, lutein showed anti-oxidative effects by up-regulates antioxidant enzymes HO-1 and NQO1. Also, we analyzed the contents of lysosome. As a result, we found that lysosome contents increased after $\mathrm{H}_{2} \mathrm{O}_{2}$ treatment and decreased after lutein treatment. These results suggest that lutein is also involved in cell metabolism. Furthermore, our results suggest that lutein prevents $\mathrm{H}_{2} \mathrm{O}_{2}$-induced cellular senescence through the scavenging of SA- $\beta$-gal positive cells. Also, lutein restores cell cycling though p53-p21 pathway regulation, up-regulates anti-senescence related protein SIRT1 and SIRT3. Thus, Lutein inhibits oxidative stress induced by ROS and protects ARPE9-19 cells from cellular senescence, especially by oxidative stress. As oxidative stress induced cellular senescence is an important factor to the pathogenesis of AMD, and we have confirmed that lutein protects ARPE-19 cells from oxidative stress induced cellular senescence. We suggest that lutein may potentially be a new, additional therapeutic strategy for the treatment of retinal-based diseases such as AMD.

\section{Acknowledgements}

Not applicable.

\section{Funding}

The present study was supported by the Basic Science Research Program through the National Research Foundation of Korea (NRF), funded by the Ministry of Education (grant nos. NRF-2018R1D1A1B07047497 and NRF-2018R1D1A3B07047983).

\section{Availability of data and materials}

All data generated or analyzed during this study are included in the published article.

\section{Authors' contributions}

SYC conducted the experimental work. SYP and GP designed and performed the experiments, and analyzed the data. SYC, SYP and GP wrote the manuscript. SYP and GP obtained financial support and supervised the study.

\section{Ethics approval and consent to participate}

Not applicable.

\section{Patient consent for publication}

Not applicable.

\section{Competing interests}

The authors declare that they have no competing interests.

\section{References}

1. Alves-Rodrigues A and Shao A: The science behind lutein. Toxicol Lett 150: 57-83, 2004.

2. Campisi J and d'Adda di Fagagna F: Cellular senescence: When bad things happen to good cells. Nat Rev Mol Cell Biol 8: 729-740, 2007.

3. Celi P: Biomarkers of oxidative stress in ruminant medicine. Immunopharmacol Immunotoxicol 33: 233-240, 2011.

4. Chen Y, Fu LL, Wen X, Wang XY, Liu J, Cheng Y and Huang J: Sirtuin-3 (SIRT3), a therapeutic target with oncogenic and tumor-suppressive function in cancer. Cell Death Dis 5: e1047, 2014.

5. Fang Y, Su T, Qiu X, Mao P, Xu Y, Hu Z, Zhang Y, Zheng X, Xie P and Liu Q: Protective effect of alpha-mangostin against oxidative stress induced-retinal cell death. Sci Rep 6: 21018, 2016.

6. Itahana K, Dimri G and Campisi J: Regulation of cellular senescence by p53. Eur J Biochem 268: 2784-2791, 2001.

7. Izumi-Nagai K, Nagai N, Ohgami K, Satofuka S, Ozawa Y, Tsubota K, Umezawa K, Ohno S, Oike Y and Ishida S: Macular pigment lutein is antiinflammatory in preventing choroidal neovascularization. Arterioscler Thromb Vasc Biol 27: 2555-2562, 2007.

8. Jeong G, Li B, Lee D, Kim KH, Lee IK, Lee KR and Kim Y: Cytoprotective and anti-inflammatory effects of spinasterol via the induction of heme oxygenase-1 in murine hippocampal and microglial cell lines. Int Immunopharmacol 10: 1587-1594, 2010.

9. Kamoshita M, Toda E, Osada H, Narimatsu T, Kobayashi S, Tsubota $\mathrm{K}$ and Ozawa Y: Lutein acts via multiple antioxidant pathways in the photo-stressed retina. Sci Rep 6: 30226, 2016.

10. Kuilman T, Michaloglou C, Mooi WJ and Peeper DS: The essence of senescence. Genes Dev 24: 2463-2479, 2010.

11. Marazita MC, Dugour A, Marquioni-Ramella MD, Figueroa JM and Suburo AM: Oxidative stress-induced premature senescence dysregulates VEGF and CFH expression in retinal pigment epithelial cells: Implications for age-related macular degeneration. Redox Biol 7: 78-87, 2016.

12. Murthy RK, Ravi K, Balaiya S, Brar VS and Chalam KV: Lutein protects retinal pigment epithelium from cytotoxic oxidative stress. Cutan Ocul Toxicol 33: 132-137, 2014.

13. Kikuchi G, Yoshida T and Noguchi M: Heme oxygenase and heme degradation. Biochem Biophys Res Commun 338: 558-567, 2005.

14. Probin V, Wang Y, Bai A and Zhou D: Busulfan selectively induces cellular senescence but not apoptosis in WI38 fibroblasts via a p53-independent but extracellular signal-regulated kinase-p38 mitogen-activated protein kinase-dependent mechanism. J Pharmacol Exp Ther 319: 551-560, 2006. 
15. Saviranta NMM, Veeroos L, Granlund LJ, Hassinen VH, Kaarniranta K and Karjalainen RO: Plant flavonol quercetin and isoflavone biochanin A differentially induce protection against oxidative stress and inflammation in ARPE-19 cells. Food Res Int 44: 109-113, 2011.

16. Supanji, Shimomachi M, Hasan MZ, Kawaichi M and Oka C: HtrAl is induced by oxidative stress and enhances cell senescence through p38 MAPK pathway. Exp Eye Res 112: 79-92, 2013.

17. Son Y, Byun SJ and Pae HO: Involvement of heme oxygenase-1 expression in neuroprotection by piceatannol, a natural analog and a metabolite of resveratrol, against glutamate-mediated oxidative injury in HT22 neuronal cells. Amino Acids 45: 393-401, 2013
18. Preyat $\mathrm{N}$ and Leo O: Sirtuin deacylases: A molecular link between metabolism and immunity. J Leukoc Biol 93: 669-680, 2013.

19. Zhuge CC, Xu JY, Zhang J, Li W, Li P, Li Z, Chen L, Liu X, Shang $\mathrm{P}, \mathrm{Xu} \mathrm{H}$, et al: Fullerenol protects retinal pigment epithelial cells from oxidative stress-induced premature senescence via activating SIRT1. Invest Ophthalmol Vis Sci 55: 4628-4638, 2014. 